\title{
Prospective evaluation of 24 hour ambulatory pH metry in Belsey Mark IV antireflux surgery
}

\author{
J M L M Horbach, A A M Masclee, C B H W Lamers, H G Gooszen
}

\begin{abstract}
This study evaluated the effect of the $270^{\circ}$ Belsey Mark IV fundoplication on 24 hour ambulatory pH metry variables. Thirty seven patients with confirmed gastrooesophageal reflux disease who had a Belsey Mark IV antireflux procedure were evaluated preoperatively and three to six months postoperatively including endoscopy, lower oesophageal sphincter manometry, and 24 hour ambulatory pH metry. In 30 of 37 patients the Belsey Mark IV fundoplication was judged successful based on symptom relief and healing of oesophagitis. In these 30 patients percentage reflux for total, upright, and supine time (median and range) decreased significantly $(\mathbf{p}<\mathbf{0 . 0 0 1})$ from $10 \cdot 0 \%(2 \cdot 7-35 \cdot 3 \%), 10 \cdot 8 \%(3 \cdot 2-39 \cdot 9 \%)$, and $6.7(0.0-33 \cdot 0 \%)$ respectively to $0.5 \%$ $(0 \cdot 0-7 \cdot 4 \%), 0 \cdot 6 \%(0 \cdot 0-13 \cdot 7 \%)$, and $0 \cdot 1 \%$ $(0 \cdot 0-4 \cdot 9 \%)$ after operation. This decrease in reflux time resulted predominantly from a significant $(p<0.001)$ reduction in the number of reflux episodes from $98(23-231)$ to $14(0-82)$ postoperatively. Normalisation of total reflux time (upper limit of normal for time with $\mathrm{pH}$ below $4: 4 \%$ ) was found in $89 \%$ and normalisation of total and upright and supine reflux in $64 \%$ of successfully operated patients with confirmed abnormal acid reflux before operation. A successful antireflux procedure was associated with significant $(\mathbf{p}<0.001)$ increases in lower oesophageal sphincter pressure from $7.8(0.6) \mathrm{mm}$
\end{abstract} Hg to $14.5(0.7) \mathrm{mm} \mathrm{Hg}$ mean (SEM). In seven patients with a failed antireflux operation basal lower oesophageal sphincter pressure did not change significantly (preoperative value $5.7(1.3) \mathrm{mm} \mathrm{Hg}$; postoperative value $7 \cdot 8(0.8) \mathrm{mm} \mathrm{Hg})$. In these patients reflux time did not decrease after the operation and remained in the abnormal range in all patients. It is concluded that a successful, in contrast with a failed, Belsey Mark IV fundoplication is associated with significant decreases in total, upright, and supine reflux time. Normalisation of pH metry variables is not a prerequisite for successful antireflux surgery. A successful $270^{\circ}$ Belsey Mark IV fundoplication was associated with a significant increase in basal lower oesophageal sphincter pressure, in contrast with the failure group. Restoration of a sufficient lower oesophageal sphincter barrier is an important aim in antireflux surgery. (Gut 1994; 35: 1529-1535)

The introduction of strong acid inhibitory drugs has dramatically improved the results of medical treatment in patients with reflux oesophagitis. ${ }^{1-4}$ With the prescription of these drugs physicians have become reluctant to refer patients with gastro-oesophageal reflux disease for antireflux surgery. A significant proportion of patients with severe reflux oesophagitis, however, either do not sufficiently respond to treatment with $\mathrm{H}_{2}$ receptor antagonists or proton pump inhibitors or require prolonged, sometimes lifelong, medical treatment. $^{245}$ It has therefore been questioned whether such patients should be offered surgery. ${ }^{6}$ Several studies have shown that antireflux surgery is very effective in the control of reflux symptoms and healing of oesophagitis. ${ }^{7-12}$ After $360^{\circ}$ Nissen fundoplication or $270^{\circ}$ Belsey Mark IV fundoplication over $85 \%$ of patients become asymptomatic or have significant improvement of symptoms with healing of oesophagitis. ${ }^{7-12}$

Twenty four hour ambulatory $\mathrm{pH}$ monitoring is now increasingly used to diagnose abnormal reflux and is currently considered the most sensitive test to detect gastrooesophageal reflux disease. ${ }^{13-16}$ Twenty four hour $\mathrm{pH}$ metry is especially helpful in diagnosing gastro-oesophageal reflux disease in patients with reflux symptoms in the absence of endoscopic oesophagitis. ${ }^{16}$ The technique is also applicable to evaluate the efficacy of medical or surgical treatment. Recent studies have shown that the Nissen fundoplication significantly decreases gastrooesophageal reflux with normalisation of 24 hour $\mathrm{pH}$ metry parameters in up to $80 \%$ of patients. ${ }^{77-20}$ Little is known, however, on the effect of the Belsey Mark IV antireflux procedure on 24 hour $\mathrm{pH}$ metry variables. The aims of this study were therefore to evaluate the efficacy of the Belsey Mark IV fundoplication with special emphasis on 24 hour $\mathrm{pH}$ metry and the relation between lower oesophageal sphincter pressure and $\mathrm{pH}$ metry data. Thirty seven patients who had a Belsey Mark IV antireflux procedure were prospectively studied. Before and after operation evaluation included standardised questionnaire for symptoms, endoscopy, lower oesophageal sphincter manometry, and 24 hour ambulatory $\mathrm{pH}$ metry. 
TABLE I Grading system to combine 'severity' and 'frequency' in scoring reflux symptoms like heartburn, regurgitation, and dysphagia

\begin{tabular}{lllll}
\hline & Severity & & & \\
\cline { 2 - 5 } Frequency & Severe & Moderate & Mild & Absent \\
\hline Daily & grade 3 & grade 2 & grade 1 & grade 0 \\
1 week & grade 2 & grade 1 & grade 1 & grade 0 \\
1 month & grade 1 & grade 1 & grade 1 & grade 0 \\
< 1 month & grade 1 & grade 1 & grade 1 & grade 0 \\
\hline
\end{tabular}

\section{Methods}

\section{PATIENTS}

Between 1982 and 1992, a consecutive group of 80 patients had a Belsey Mark IV operation as primary antireflux procedure for gastrooesophageal reflux disease at our institution. All patients had symptoms suggestive of gastro-oesophageal reflux disease such as heartburn, regurgitation, retrosternal pain or oesophageal dysphagia. The diagnosis of gastro-oesophageal reflux disease was confirmed in all patients either by endoscopy showing oesophagitis or by ambulatory 24 hour $\mathrm{pH}$ monitoring showing an increased oesophageal exposure time to acid gastric juice, or both. Preoperative investigation included oesophageal manometry. Of 80 patients, 37 patients (18 male, 19 female; mean age 47 years, range 27-75) agreed to participate in a study evaluating the effect of the Belsey Mark IV antireflux procedure. Evaluation before and after surgery included scoring of reflux related symptoms, upper gastrointestinal endoscopy, oesophageal manometry, and 24 hour ambulatory $\mathrm{pH}$ monitoring. Postoperative evaluation was performed three to six months after the operation. Before and after operation reflux related symptoms were scored by a standardised questionnaire. Heartburn/retrosternal pain was defined as any painful or burning sensation

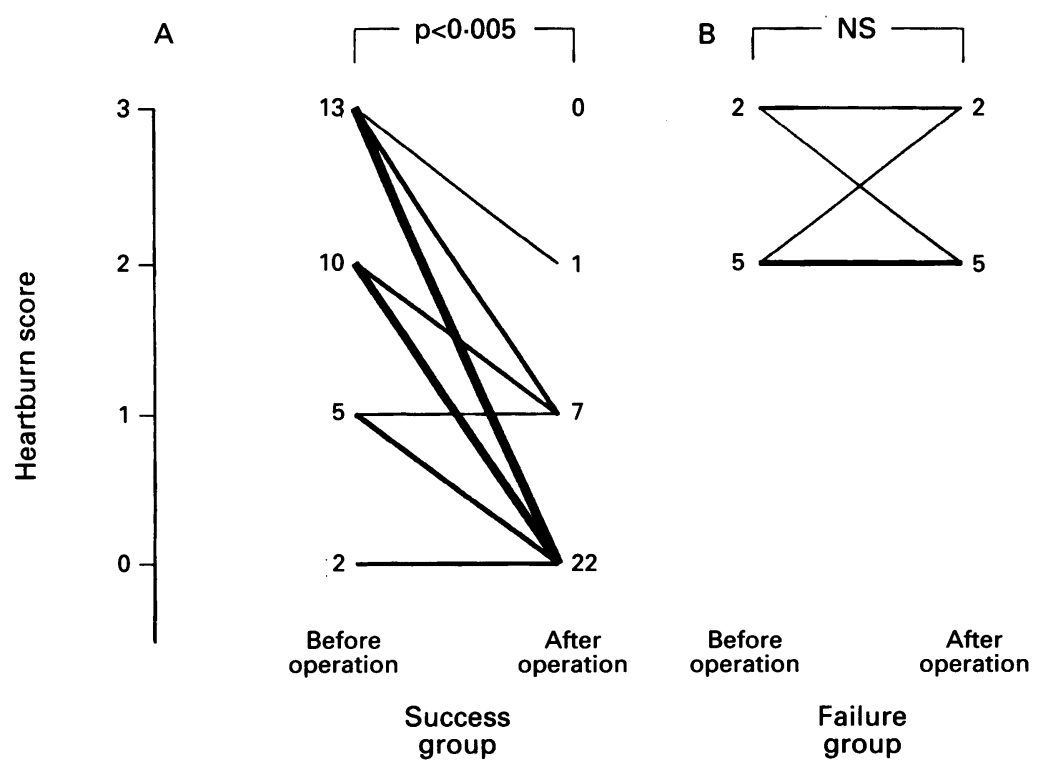

Figure 1: Effect of the Belsey Mark IV antireflux procedure on symptoms of heartburn using a composite score for severity and frequency. $(A): 30$ patients with a successful procedure; (B): 7 patients with a failed procedure. behind the sternum or the subxiphoid region, or both with or without a relation to food intake or posture. For regurgitation any sensation of spontaneous bringing up of gastrointestinal contents into the pharynx or the mouth was used for definition and dysphagia was defined as an uncomfortable sticking sensation during or shortly after eating. Table I shows that we combined severity and frequency for the presentation of symptoms.

Of these 37 patients, in 30 the operation was judged successful $(81 \%)$ and in seven patients the antireflux procedure had failed (19\%). Successful antireflux surgery was defined (a) subjectively, as complete relief or major improvement of symptoms without further need for medical treatment and without interfering with daily life and (b) objectively, as no endoscopic signs of oesophagitis without drug treatment. Of the remaining 43 patients, in 16 no preoperative $\mathrm{pH}$ data were available, 26 patients refused postoperative $\mathrm{pH}$ monitoring, and two patients died nine months and one year after operation resulting from causes not related to gastro-oesophageal reflux disease or the antireflux procedure. In these 43 patients the antireflux procedure was judged successful in $84 \%$ based on symptomatic recovery and in $88 \%$ based on endoscopic healing of oesophagitis. Thus the group of 37 patients in whom a complete postoperative evaluation was performed is thought to be representative for the whole group of operated patients.

The indications for antireflux surgery were the presence of reflux symptoms plus either endoscopic oesophagitis or abnormal gastrooesophageal reflux (pH metry), when (a) not sufficiently responding to prolonged medical treatment ( $>6$ months) or (b) responding to medical therapy but requiring maintenance treatment.

The surgical procedures were performed by two of the authors ( $\mathrm{J} \mathrm{H}$ and $\mathrm{H} \mathrm{G}$ ). In all patients a $270^{\circ}$ fundoplication with creation of a posterior buttress of the right crus was performed through a left sided thoracotomy in the sixth intercostal space, as outlined by Belsey. ${ }^{21}$ On the seventh postoperative day the correct position of the fundoplication below the diaphragm was confirmed through an oesophagogram in all 37 patients.

Two senior gastroenterologists performed all endoscopies before and after surgery. The severity of oesophagitis was graded endoscopically according to the criteria of Savary and Miller. ${ }^{22}$ In the successfully operated group, preoperative endoscopy showed oesophagitis grade 0 in five patients, grade $I$ in nine patients, grade II in 13 patients, grade III in two patients, and grade IV in one patient. All patients with grade 0 oesophagitis had abnormal acid reflux determined by 24 hour $\mathrm{pH}$ metry. Oesophagitis was not found in any of these 30 patients after operation. Of seven patients with a failed antireflux procedure, preoperative endoscopy showed oesophagitis grade 0 in 1 patient, grade $I$ in two patients, grade II in three patients, and grade IV in one patient. Postoperative endoscopy showed 
TABLE II Dysphagia scores before and three to six months after Belsey Mark IV operation in 37 patients. Score fell in 14 patients, remained the same in 21 patients, and rose in 2 patients

\begin{tabular}{lll}
\hline & \multicolumn{2}{l}{ Patient $(n)$} \\
\cline { 2 - 3 } Dysphagia score & Before operation & After operation \\
\hline grade 3 & 4 & 0 \\
grade 2 & 5 & 4 \\
grade 1 & 10 & 8 \\
grade 0 & 18 & 25 \\
\hline
\end{tabular}

oesophagitis grade 0 in one patient, grade $I$ in one patient, and grade II in five patients.

\section{REFLUX SYMPTOMS}

Before operation, 13 patients in the successfully operated group had 'severe' heartburn, 10 had 'moderate', and five had 'mild' heartburn (Fig 1A). In two patients this symptom was absent but these patients had symptoms of regurgitation. All patients, except one, improved after the operation to moderate $(n=1)$, mild $(n=7)$ or were free of heartburn $(n=22)$. In the group of seven patients with a failed antireflux procedure one patient improved, one deteriorated, and five were unchanged with respect to heartburn symptoms (Fig 1B). For regurgitation the effect of operation was similar to the effect on heartburn (data not shown). Dysphagia was present in 19 of 37 patients before operation (Table II). After surgery dysphagia scores improved in 14 patients, were unchanged in 21 patients, and deteriorated in two patients (from absent to moderate in one, from mild to moderate in the other).

\section{MANOMETRY OF THE LOWER OESOPHAGEAL SPHINCTER}

Manometry of the lower oesophageal sphincter was performed after an overnight fast using a small polyvinyl 4 lumen composite side hole catheter. The orifices were placed $5 \mathrm{~cm}$ apart and oriented radically at $90^{\circ}$ to each other around the circumference. The catheters were perfused with distilled water at a constant rate of $0.5 \mathrm{ml} / \mathrm{min}$ using a low compliance pneumohydraulic capillary perfusion pump (Arndorfer Medical Specialties, Greendale, WI). The recording catheter was passed transnasally into the stomach and withdrawn at $0.5 \mathrm{~cm}$ intervals into the oesophagus using the stationary pull through technique. Thus, the mean of four end expiratory lower oesophageal sphincter pressures was obtained. The end expiratory gastric baseline pressure served as the zero reference point.

\section{CONTINUOUS PH MONITORING}

Intraoesophageal $\mathrm{pH}$ was measured every six seconds for 24 hours using a glass electrode with internal reference (GK 2801C, Radiometer, Copenhagen). These six second interval $\mathrm{pH}$ tracings were stored on solid state devices with a $15 \mathrm{~K}$-byte memory (Proxima Light, Mantova, Italy). After completion of each 24 hour investigation data were transferred to floppy disks using an Olivetti personal computer (M24). Electrodes and recorders were calibrated at $20^{\circ} \mathrm{C}$ using buffer solutions of $\mathrm{pH} 7.00$ and 4.01 (Ingold AG). Temperature correction for intraoesophageal readings $\left(37^{\circ} \mathrm{C}\right)$ was automatically performed. The calibration procedure was checked manually before starting every experiment and, to assess electrode stability repeated afterwards. An electrode drift of $\leqslant 0 \cdot 1 \mathrm{pH}$ unit was considered acceptable. After calibration the electrode was passed transnasally and positioned $5 \mathrm{~cm}$ above the manometrically determined upper margin of the lower sphincter. The reflux parameters were calculated for the 24 hour data using a commercially available analysis program (Proxima). Reflux parameters used in this study were percentage of time with $\mathrm{pH}<4$ for total recording time, time in upright and time in supine position, number of reflux episodes with $\mathrm{pH}<4$ (total upright, supine), and mean duration of reflux episodes (total, upright, supine). All treatment that could possibly interfere with the results was stopped at least 48 hours before pH metry. Abnormal reflux was defined as total percentage of time with $\mathrm{pH}$ below $4 \geqslant 4 \cdot 0 \%$, upright $\geqslant 4 \cdot 4 \%$, and supine $\geqslant 1 \cdot 2 \%{ }^{16}$

\section{STATISTICAL ANALYSIS}

Results of lower oesophageal sphincter pressure are expressed as mean (SEM). Results of 24 hours $\mathrm{pH}$ metry are expressed as medians and ranges. The paired Wilcoxon signed rank test was used for statistical analysis between symptom scores and reflux variables from $\mathrm{pH}$

TABLE III Reflux variables before and after operation in 30 patients with a successful and 7 patients with a failed $270^{\circ}$ Belsey Mark IV fundoplication. (Values are expressed as median and ranges)

\begin{tabular}{|c|c|c|c|c|c|c|}
\hline & \multicolumn{3}{|c|}{ Successful group $(n=30)$} & \multicolumn{3}{|c|}{ Failure group $(n=7)$} \\
\hline & Total & Upright & Supine & Total & Upright & Supine \\
\hline $\begin{array}{l}\text { Time } \mathrm{pH}<4(\%) \\
\text { before operation } \\
\text { after operation } \\
\text { Reflux episodes }\end{array}$ & $\begin{array}{c}10 \cdot 0(2 \cdot 7-35 \cdot 3) \\
0 \cdot 5(0 \cdot 0-7 \cdot 4)^{\star \star}\end{array}$ & $\begin{array}{l}10.8(3.2-39.9) \\
0.6(0.0-13 \cdot 7)^{\star \star}\end{array}$ & $\begin{array}{l}6 \cdot 7(0 \cdot 0-33 \cdot 0) \\
0 \cdot 1(0 \cdot 0-4 \cdot 9)^{\star \star}\end{array}$ & $\begin{array}{r}8 \cdot 3(4 \cdot 3-13 \cdot 6) \\
11 \cdot 3(5 \cdot 2-19 \cdot 1)\end{array}$ & $\begin{array}{l}8 \cdot 6(4 \cdot 8-22) \\
5 \cdot 9(1 \cdot 7-24 \cdot 8)\end{array}$ & $\begin{array}{r}7 \cdot 0(0 \cdot 0-22 \cdot 6) \\
12 \cdot 2(0 \cdot 8-24 \cdot 4)\end{array}$ \\
\hline $\begin{array}{l}\text { before operation } \\
\text { after operation }\end{array}$ & $\begin{array}{l}98(23-231) \\
14(0-82)^{\star \star}\end{array}$ & $\begin{array}{r}67(15-193) \\
7(0-74)^{\star \star}\end{array}$ & $\begin{array}{l}13(0-124) \\
3(0-20)^{\star \star}\end{array}$ & $\begin{array}{l}76(41-146) \\
83(47-141)\end{array}$ & $\begin{array}{l}69(34-126) \\
42(23-101)\end{array}$ & $\begin{array}{c}7(1-21) \\
49(2-71)^{\star \star}\end{array}$ \\
\hline $\begin{array}{l}\text { Duration of reflux ep } \\
\text { before operation } \\
\text { after operation }\end{array}$ & $\begin{array}{l}\text { pisode (min) } \\
1.3(0 \cdot 6-5 \cdot 4) \\
0.9(0.1-11 \cdot 8)\end{array}$ & $\begin{array}{l}1 \cdot 2(0 \cdot 6-4 \cdot 4) \\
0 \cdot 7(0 \cdot 1-2 \cdot 6)^{\star}\end{array}$ & $\begin{array}{l}1.8(0 \cdot 4-10 \cdot 1) \\
0.9(0 \cdot 2-11 \cdot 8)\end{array}$ & $\begin{array}{l}1 \cdot 4(0 \cdot 7-4 \cdot 3) \\
2 \cdot 0(0 \cdot 8-3 \cdot 2)\end{array}$ & $\begin{array}{l}1.4(0.4-2.3) \\
0.8(0.4-3.2)\end{array}$ & $\begin{array}{l}3 \cdot 4(0 \cdot 1-17 \cdot 6) \\
2 \cdot 5(0 \cdot 7-6 \cdot 8)\end{array}$ \\
\hline
\end{tabular}

Postoperative compared with preoperative. ${ }^{\star} \mathrm{p}<0.05 ;{ }^{\star \star} \mathrm{p}<0.001$. 


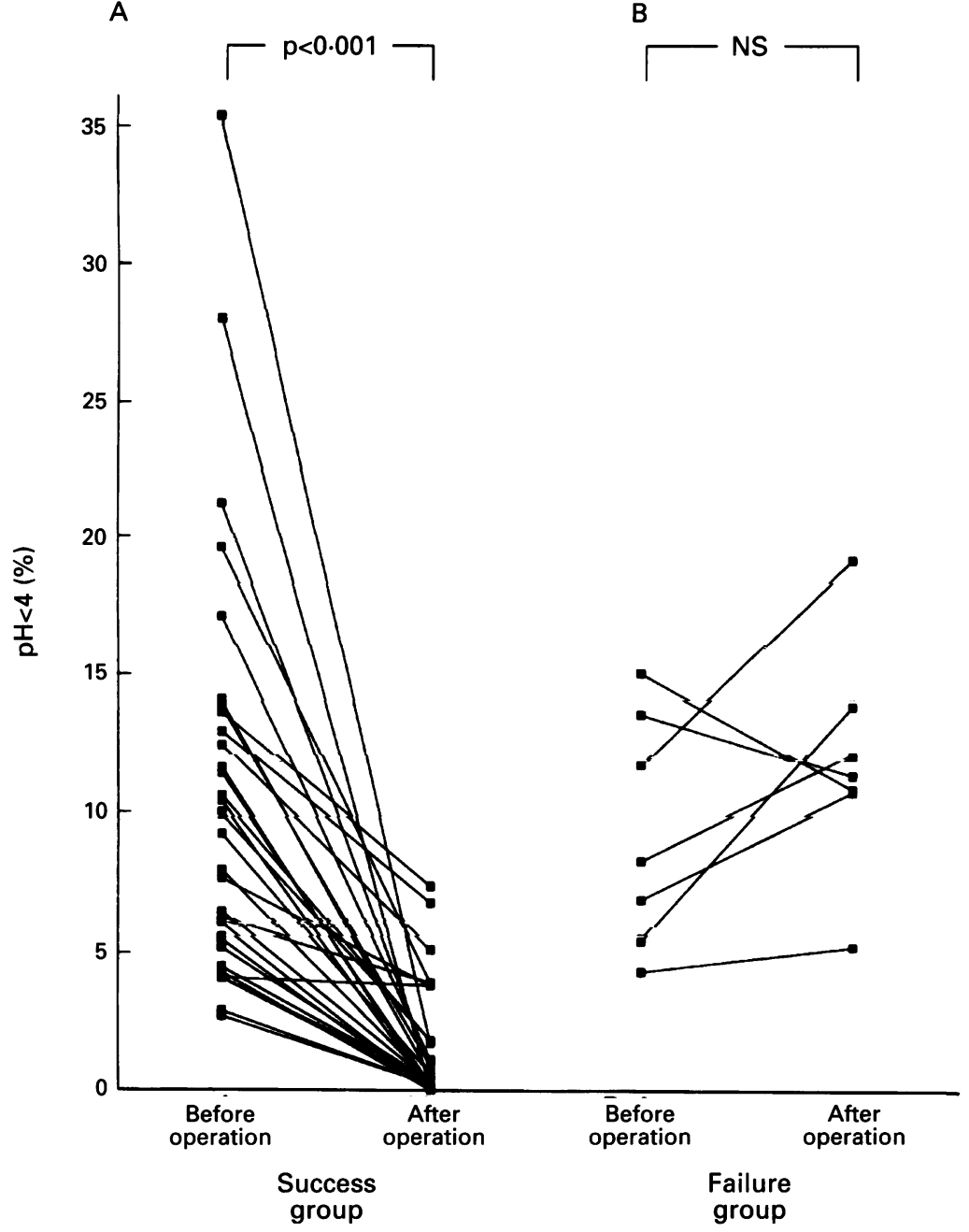

Figure 2: Individual data of percentage of total recording time with $\mathrm{pH}<4$ before and after operation in 30 patients with a successful $(A)$ and 7 patients with a failed Belsey Mark IV antireflux procedure (B). decrease resulted from a significant $(\mathrm{p}<0.001)$ reduction in the number of reflux episodes, both upright and supine. Although the duration of reflux episodes decreased postoperatively in the successful group, this reduction was significant $(p<0.05)$ only for the reflux episodes in upright position.

In the failure group no significant changes in reflux parameters between preoperative and postoperative values were seen apart from a significant $(p<0.001)$ increase in the number of postoperative supine reflux episodes. With the number of supine reflux episodes increasing postoperatively, however, the duration of supine reflux episodes decreased from $3.4(0 \cdot 1-17 \cdot 6)$ minutes to $2 \cdot 5(0 \cdot 7-6 \cdot 8)$ minutes and therefore reflux time in the supine position did not increase significantly after the operation in the failure group.

Comparing postoperative reflux parameters between the successful and the failure group, the percentages of reflux time and numbers of reflux episodes were significantly $(p<0.01)$ increased in the failure group, whereas the duration of reflux episodes was not significantly different.

According to our previously determined cut off limits to distinguish abnormal from normal acid reflux, 28 of 30 successfully operated patients had abnormal acid reflux with a total reflux time $\geqslant 4 \%$ before operation. In two patients total reflux time was below $4 \%$. One patient had abnormal upright reflux ( $4.5 \%$; normal value $\leqslant 4.4 \%$ ) and the other patient had abnormal supine reflux $(2.3 \%$; normal value $\leqslant 1 \cdot 2 \%$ ). All seven patients with a failed antireflux procedure had abnormal total reflux time, pre and postoperatively. Of 28 patients in the successful group with a total reflux time of $>4 \%$ preoperatively, $25(89 \%)$ showed normalisation of total reflux time after operation. In the three other patients in the successful group total reflux time decreased from $13 \%, 12.7 \%$, and $13 \cdot 7 \%$ to $6 \cdot 8 \%, 5 \cdot 1 \%$, and $7 \cdot 4 \%$ respectively after the antireflux procedure. None of these three patients had reflux symptoms or endoscopic signs of oesophagitis. Although total reflux time normalised postoperatively in 25 of 28 patients from the successful group, supine reflux time was above the upper limit of normal of $1.2 \%$ postoperatively in seven of these 25 patients (patient range 1.3 to $4.9 \%$ ).

\section{Results}

Table III shows the results of pre and postoperative ambulatory 24 hour $\mathrm{pH}$ metry in patients with a successful and failed Belsey Mark IV operation. Comparison of preoperative $\mathrm{pH}$ data between the successfully operated and the failure group showed no significant differences apart from the number of reflux episodes in the supine position, which was significantly higher $(p<0.05)$ in the successful group. The duration of reflux episodes tended to be longer preoperatively in the failure group but this difference was not statistically significant.

Compared with preoperative values, in the successful group total reflux time (Fig 2), upright and supine reflux time decreased significantly $(p<0.001)$ after operation. This

\section{LOWER OESOPHAGEAL SPHINCTER PRESSURE}

Basal preoperative lower oesophageal between successfully operated patients $(7 \cdot 8$ $(0.6) \mathrm{mm} \mathrm{Hg})$ and the failure group (5.7 (1.3) $\mathrm{mm} \mathrm{Hg})$. After surgery a significant $(\mathrm{p}<0.001)$ increase in lower oesophageal sphincter pressure from $7.8(0.6) \mathrm{mm} \mathrm{Hg}$ to $14.5(0.7)$ $\mathrm{mm} \mathrm{Hg}$ was seen in the successfully operated group (Fig 3). In the failure group lower oesophageal sphincter pressure increased from $5 \cdot 7(1.3) \mathrm{mm} \mathrm{Hg}$ to $7 \cdot 8(0.8) \mathrm{mm} \mathrm{Hg}$ postoperatively (NS). Postoperative lower oesophageal sphincter pressure values were significantly $(p<0.001)$ higher in the successful group compared with the failure group. sphincter pressure did not significantly differ 
A

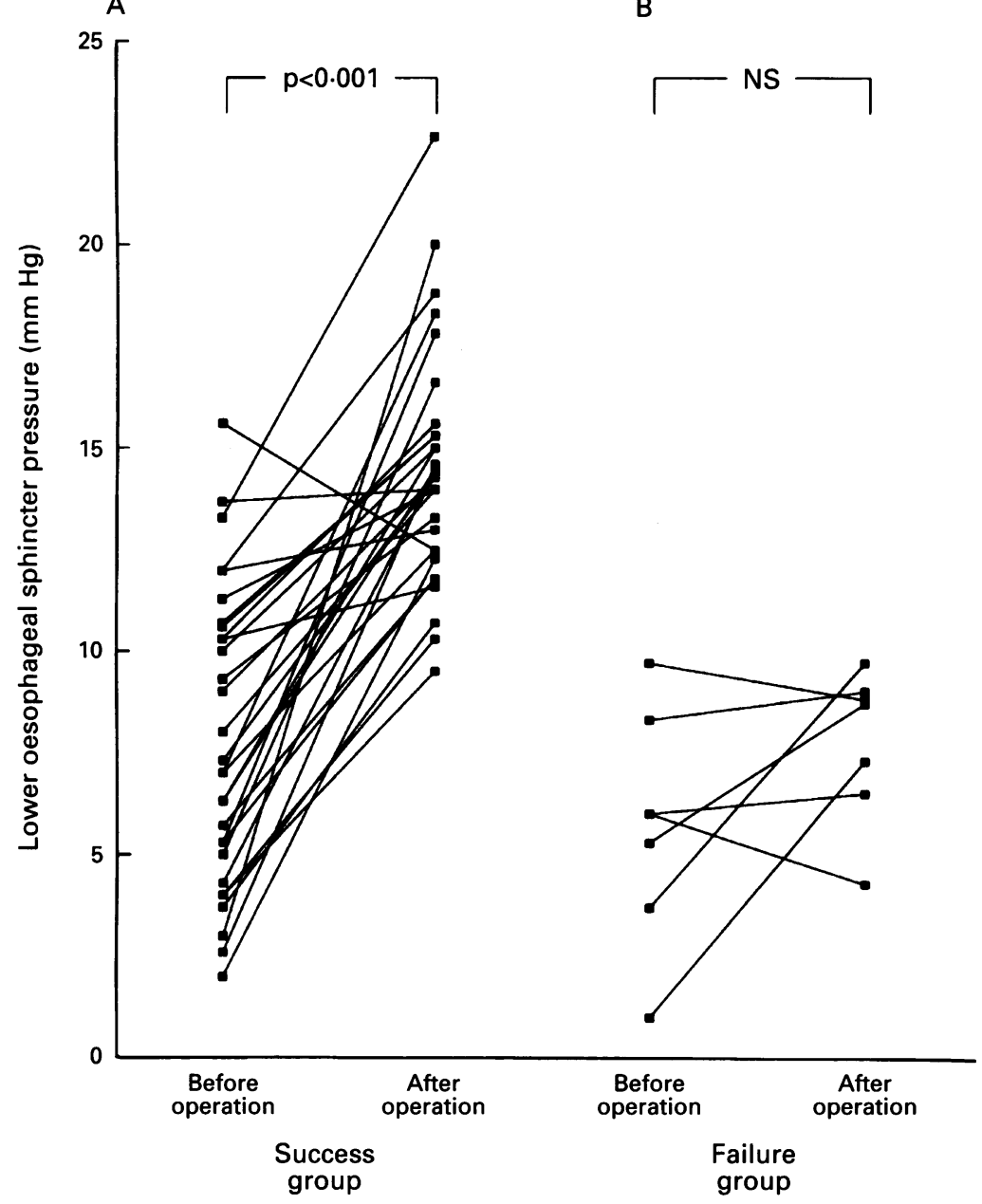

Figure 3: Individual data of basal lower oesophageal sphincter pressure ( $\mathrm{mm} \mathrm{Hg}$ ) before and after operation in 30 patients with a successful $(A)$ and 7 patients with a failed Belsey Mark IV antireflux procedure (B).

In Fig 4 the correlation between basal lower oesophageal sphincter pressure and total reflux time pre and postoperatively in all 37 patients is shown. Before and after operation reflux time showed a significant inverse trend with lower oesophageal sphincter pressure (preoperative $r=-0.436, \mathrm{p}<0.01$; postoperative $r=-0.644, \mathrm{p}<0.001)$. After operation, none of the patients with a lower oesophageal sphincter

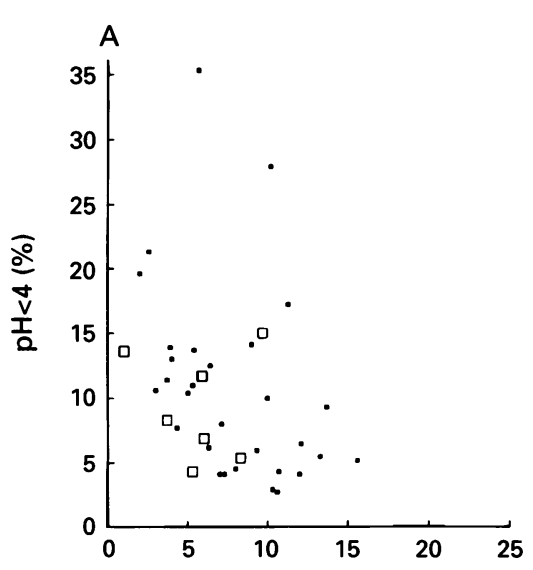

Lower oesophageal sphincter pressure $(\mathrm{mm} \mathrm{Hg})$

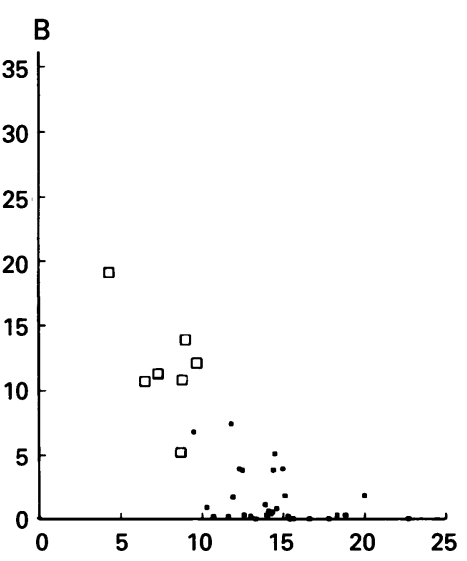

Lower oesophageal sphincter pressure $(\mathrm{mm} \mathrm{Hg})$
Figure 4: Relation between individual data of lower oesophageal sphincter pressure and reflux time (\% total time with $p H<4$ ) before operation $(A: \mathrm{r}=-0.436, p<0.01)$ and after operation ( $B: \mathrm{r}=-0.644, p<0.001$ ) in 37 patients with gastro-oesophageal reflux disease who had a Belsey Mark IV fundoplication. Dots represent patients with a successful operation and squares represent patients in whom the operation had failed. pressure $\geqslant 16 \mathrm{~mm} \mathrm{Hg}$ had an abnormal acid reflux whereas abnormal acid reflux (total reflux time $>4 \%$ ) was seen in all patients with a lower oesophageal sphincter pressure $\leqslant 10 \mathrm{~mm} \mathrm{Hg}$. With a postoperative lower oesophageal sphincter pressure value between 10 and $16 \mathrm{~mm} \mathrm{Hg}$ abnormal acid reflux was seen in three patients.

\section{Discussion}

Although it is well known that antireflux surgery is effective in reducing reflux symptoms and healing oesophagitis, ${ }^{7-12}$ it has only been recently shown by 24 hour ambulatory $\mathrm{pH}$ metry that antireflux surgery effectively reduces gastric acid reflux into the oesophagus. ${ }^{7}{ }^{17-20}$ Since its introduction by Johnson and de Meester ${ }^{23}$ in 1974, 24 hour pH metry has been claimed to be the most sensitive test to detect gastro-oesophageal reflux disease $\mathrm{13}^{16}$ and this is possibly true for the evaluation of medical and surgical antireflux treatment. After Nissen fundoplication exposure time of the distal oesophagus to gastric acid (\% of total time with $\mathrm{pH}<4$ ) decreases significantly and is even completely abolished in up to $40 \%$ operated patients. ${ }^{77-20}$ Although the Belsey Mark IV antireflux procedure is as effective as the Nissen fundoplication with regard to symptomatic and endoscopic improvement, ${ }^{1011}$ little is known on the effect of the Belsey Mark IV operation on 24 hour $\mathrm{pH}$ metry variables. In this study 37 patients who had a Belsey Mark IV fundoplication for gastro-oesophageal reflux disease were prospectively studied with 24 hour pH metry performed before and three to six months after operation. In the 30 patients who successfully had a Belsey Mark IV fundoplication, the percentage of time with $\mathrm{pH}$ below 4 decreased significantly for total time, time in upright position, and time in supine position. This decrease in acid exposure time resulted mainly from a significant reduction in the number of reflux episodes both in upright and supine position. For upright reflux a significant reduction in the duration of reflux episodes was also seen.

Previous studies have pointed to the role of the lower oesophageal sphincter in preventing gastro-oesophageal reflux. ${ }^{2425}$ Apart from a defective lower oesophageal sphincter or very low oesophageal sphincter pressure, it is now well established that transient lower oesophageal sphincter relaxations constitute the most important mechanism of gastrooesophageal reflux both in healthy subjects and patients with gastro-oesophageal reflux disease. ${ }^{25}$ The precise mechanisms of a surgically created antireflux barrier to prevent gastrooesophageal reflux are not yet known. In the successfully operated patients a significant increase in lower oesophageal sphincter pressure after the operation was associated with a significant decrease in acid reflux time. Our results confirm those of previous studies that the creation of a sufficient lower oesophageal sphincter barrier is important in preventing or 
reducing gastro-oesophageal reflux. ${ }^{826-28}$ In the postoperative patients an inverse relation between lower oesophageal sphincter pressure and reflux time could be shown. In patients with a postoperative basal lower oesophageal sphincter pressure value of $\geqslant 16 \mathrm{~mm} \mathrm{Hg}$ abnormal reflux did not occur whereas all patients with a basal lower oesophageal sphincter pressure value of $\leqslant 10 \mathrm{~mm} \mathrm{Hg}$ had abnormal acid reflux.

An increase in lower oesophageal sphincter pressure is thought to be important in preventing supine or night time reflux because supine reflux occurs mainly through a defective lower oesophageal sphincter and not through transient lower oesophageal sphincter relaxations that occur almost exclusively while awake. ${ }^{29}$ An increase in lower oesophageal sphincter pressure after the operation, however, was associated not only with a decrease in supine reflux but also with a significant decrease in upright reflux, when patients are awake and reflux mainly occurs through transient lower oesophageal sphincter relaxations. It is not known whether the Belsey Mark IV procedure prevents the occurrence of transient lower oesophageal sphincter relaxations or reduces the number of transient lower oesophageal sphincter relaxations associated with reflux. Postoperative manometry in our patients showed that after a $270^{\circ}$ Belsey Mark IV fundoplication the lower oesophageal sphincter relaxes completely upon swallowing, in contrast with a $360^{\circ}$ Nissen fundoplication. ${ }^{30}$ Thus, complete transient lower oesophageal sphincter relaxations reaching zero gastric baseline pressure may be present after Belsey Mark IV operation.

After Nissen fundoplication total, upright, and supine reflux time decrease significantly although normalisation of 24 hour $\mathrm{pH}$ metry variables is less frequently found than symptomatic relief or healing of oesophagitis. ${ }^{7}$ 17-20 In our study total reflux time normalised postoperatively in 25 of 28 successfully operated patients with total reflux time $>4 \%$ preoperatively. In three patients, however, abnormal reflux persisted despite clinical and endoscopic improvement. When analysing the postoperative $\mathrm{pH}$ metry data in more detail, seven of 25 patients with normalisation of total reflux time postoperatively, still had abnormal supine reflux with values above the upper limit of normal of $1 \cdot 2 \%$. Thus, successful antireflux surgery defined as improvement or absence of reflux symptoms and absence of oesophagitis does not necessarily require complete normalisation of $\mathrm{pH}$ metry data.

The seven patients in whom antireflux surgery was not successful could not be distinguished preoperatively from the successful group based on endoscopic grade of oesophagitis, basal lower oesophageal sphincter pressure or $24 \mathrm{pH}$ metry data. This is in agreement with a previous finding of Mughal et al. ${ }^{31}$ Postoperative lower oesophageal sphincter pressure showed no significant increase in these patients and values were below $10 \mathrm{~mm} \mathrm{Hg}$ in all. Reflux time did not significantly decrease after operation and remained in the abnormal range in all patients. The total number of reflux episodes did not significantly change after operation although upright reflux episodes decreased and supine reflux episodes increased significantly.

Reflux symptoms with $\geqslant$ grade 2 persisted in all seven patients with a failed antireflux procedure. Dysphagia improved or was unchanged in 35 of 37 patients. In two patients, however, dysphagia symptoms deteriorated (from mild to moderate in one, from absent to moderate in the other). One patient was successfully operated on and had a postoperative lower oesophageal sphincter pressure of $18 \mathrm{~mm}$ with complete relaxation of the lower oesophageal sphincter after swallowing. In the other patient the reflux procedure had failed. This patient had a postoperative lower oesophageal sphincter pressure of $9 \mathrm{~mm}$ $\mathrm{Hg}$ with complete lower oesophageal sphincter relaxation after swallowing. In this case dysphagia may result from causes other than a strict mechanical origin. Thus, no mechanical barrier at the level of the lower oesophageal sphincter was present and none had gas bloat syndrome.

It is concluded that a successful $270^{\circ}$ Belsey Mark fundoplication significantly decreases total, upright, and supine reflux time. Normalisation of total reflux time was obtained in $89 \%$ of successfully operated patients and $11 \%$ had abnormal reflux time in the absence of reflux symptoms or signs. Complete normalisation with total and upright and supine reflux time below the upper limits of normal was obtained in $64 \%$ (18 of 28 ) of successfully operated patients with abnormal $\mathrm{pH}$ metry preoperatively. Thus, normalisation of 24 hours $\mathrm{pH}$ metry is not a prerequisite for successful antireflux surgery. In the patients with failed antireflux surgery no significant changes in reflux time were found and a successful $270^{\circ}$ Belsey Mark IV operation was associated with a significant increase in lower oesophageal sphincter pressure, in contrast with the failure group. The restoration of a sufficient lower oesophageal sphincter barrier is an important aim in antireflux surgery.

The authors are indebted to Mrs C de Jong, Mrs A Jongma, and Mrs B van Velzen for their technical assistance and to Mrs L Niepoth for secretarial assistance.

1 Sandmark S, Carlsson R, Fausa O, Lundell L. Omeprazole or ranitidine in the treatment of reflux esophagitis. Results of a double-blind, randomized, Scandinavian multicenter study. Scand f Gastroenterol 1988; 23: 625-32.

2 Hetzel DJ, Dent J, Reed WP, et al. Healing and relapse of severe peptic esophagitis after treatment with omeprazole. severe peptic esophagitis after trea

3 Klinkenberg-Knol EC, Jansen JBMJ, Lamers CBHW, Nelis F, Snel C, Meuwissen SGM. Use of omeprazole in the management of reflux oesophagitis resistant to $\mathrm{H}_{2}$ receptor antagonists. Scand f Gastroenterol 1989; 24: 88-93.

4 Glise $\mathrm{H}$. Healing relapse rates and prophylaxis of reflux esophagitis. Scand $\mathcal{f}$ Gastroenterol 1989; (suppl 104) 57-64.

5 Lieberman DA. Medical therapy for chronic reflux esophagitis: long term follow-up. Arch Intern Med 1987 147: $1717-20$.

6 Dehn TCB. Surgery for uncomplicated gastro-oesophageal reflux. Gut 1992; 33: 293-4.

7 Bushkin FL, Neustein CL, Parker TH, Woodward ER Nissen fundoplication for peptic reflux esophagitis. $A m \mathcal{F}$ Surg 1977; 185: 672-7.

8 De Meester TR, Bonavina L, Albertucci M. Nissen fundoplication for gastroesophageal reflux disease. Evaluation of primary repair in 100 consecutive patients. Ann Surg of primary repair 
9 Shirazi SS, Schulze K, Soper ST. Long-term follow-up for treatment of complicated chronic reflux esophagitis. Arch Surg 1987; 122: 548-52.

10 Stipa S, Fegiz G, Lascone C, et al. Belsey and Nissen operations for gastroesophageal reflux. Ann Surg 1989; 210: 583-9.

11 Salama FD, Lamont G. Long-term results of the Belsey Mark IV antireflux operation in relation to the severity of
esophagitis. F Thorac Cardiovasc Surg 1990; 100: 517-9.

12 Spechler SJ. Comparison of medical and surgical therapy for complicated gastroesophageal reflux disease in veterfor complicated gastroesophageal reflux

13 De Meester TR, Wang CI, Wernly JA, et al. Technique, indications and clinical use of 24 hour esophageal indications and clinical use of 24 hour esophageal 656-70.

14 Fink SM, McCallum RW. The role of prolonged oesophageal $\mathrm{pH}$ monitoring in the diagnosis of gastroesophageal reflux. $\mathscr{f} A M A 1984 ; 252$ : $1160-4$.

15 Schindlbeck NE, Heinrich C, Konig A, et al. Optimal thresholds, sensitivity and specificity of long term $\mathrm{pH}$ metry for the detection of gastroesophageal reflux disease. Gastroenterology 1987; 98: 85-90.

16 Masclee AAM, De Best ACAM, De Graaf R, Cluysenaar OJJ, Jansen JBMJ. Ambulatory 24-hours pH metry in the diagnosis of gastroesophageal reflux disease. Scand 7 diagnosis of gastroesophageal

17 Johnsson F, Joelsson B, Gudmundsson K, Florén $\mathrm{CH}$, Walther B. Effects of fundoplication on the antireflux mechanism. Br F Surg 1987; 74: 1111-4.

18 O'Hanrahan T, Parples M, Bancewicz J. Recurrent reflux and wrap disruption after Nissen fundoplication: detection, incidence, timing. Br $\mathcal{F}$ Surg 1990; 77: 545-7.

19 Breumelhof R, Smout AJPM, Schijns MWRJ, Bronzwaer PWA, Akkermans LMA, Jansen A. Prospective evaluation of the effects of Nissen fundoplication on gastroof

20 Martinez De Haro LF, Ortiz A, et al. Long-term results of Nissen fundoplication in reflux esophagitis without strictures. Clinical, endoscopic and $\mathrm{pH}$-metric evaluation. Dig Dis Sci 1992; 37: 523-7.

21 Belsey RHR. Transthoracic partial fundoplication (Belsey repair). In: Jamieson GG, ed. Surgery of the esophagus. London: Churchill Livingstone, 1988.

22 Savary M, Miller G. The esophagus. In: Handbook and atlas of endoscopy. Gassman: Solothurn, 1977.

23 Johnson LF, De Meester TR. Twenty-four hour pH monitoring of the distal esophagus. Quantitative measure of gastroesophageal reflux. Am f Gastroenterol 1974; 63: 325-32.

24 Dodds WJ, Dent J, Hogan WJ, et al Mechanisms of gastroesophageal reflux in patients with reflux esophagitis. NEng ₹ Med 1982; 307: 1547-52.

25 Dent J, Holloway RH, Toouli, Dodds WJ. Mechanisms of lower oesophageal sphincter incompetence in patients with symptomatic gastro-oesophageal reflux. Gut 1988; 29: $1020-8$

26 Ellis FH, Crozier RE. Reflux control by fundoplication: a clinical and manometric assessment of the Nissen operation. Ann Thorac Surg 1984; 38: 387-92.

27 Bancewicz J, Mughal M, Marples M. The lower esophageal sphincter after floppy Nissen fundoplication. $B r \mathcal{F}$ Surg 1987; 74: 162-4.

28 Johnsson F, Joelsson B, Ilberg PE. Ambulatory 24 hour intra-oesophageal $\mathrm{Ph}$ monitoring in the diagnosis of gastro-oesophageal reflux disease. Gut 1987; 28: gastro-oes $1145-50$.

29 Freidin N, Fisher MJ, Taylor W, Boyd D, Surratt P, McCallum RW, et al. Sleep and nocturnal acid reflux in normal subjects and patients with reflux oesophagitis. Gut 1991; 32: 1275-9.

30 Ireland AC, Holloway RH, Toouli J, Dent J. Mechanisms underlying the antireflux action of fundoplication. Gut 1993; 34: 303-18.

31 Mughal MM, Bancewicz J, Marples M. Oesophageal manometry and $\mathrm{pH}$ recording does not predict the bad results of Nissen fundoplication. Br f Surg 1990; 707: 43-5. 